\title{
EDUCAÇÃO AMBIENTAL EM ESPAÇOS NÃO FORMAIS: RELATO DE EXPERIÊNCIA NO PARQUE DAS AVES (FOZ DO IGUAÇU, PR, BRASIL)
}

\author{
Kerlen Alana Santa Ana Santos ${ }^{1}$ \\ Rodrigo de Cássio da Silva²
}

\begin{abstract}
Resumo: O campo da Educação Ambiental surgiu por volta do séc. $X X$, e vem sendo muito necessária, devido aos impactos ambientais que a natureza e os seres vivos enfrentam. E é nos contextos formais e não formais, que cada vez mais a Educação Ambiental amplia sua área de alcance. O presente trabalho tem por objetivo relatar uma experiência vivida por meio de um estágio em um espaço não formal de educação, o Parque das Aves - Foz do Iguaçu/PR - Brasil, onde essa prática é muito valorizada. A instituição tem enfoque na conservação de espécies de aves ameaçadas de extinção da Mata atlântica, e na formação do pensamento crítico de seus visitantes. Foram feitas reflexões sobre o papel da Educação Ambiental nesses espaços e relatadas várias contribuições para a formação de educadores ambientais mais engajados, além de esses espaços sensibilizarem os visitantes e estimularem mudanças de atitudes em relação às questões ambientais.
\end{abstract}

Palavras-chave: Educação Ambiental; Espaços Não Formais; Experiência.

Abstract: The Environmental Education issue emerged around the 20th century, and it is become very necessary, due to the environmental impacts faced to nature and living beings. And it is in the formal and non-formal spaces that Environmental Education increasingly broadens its scope. This paper aims to report an experience lived through an internship in a non-formal education space, the Bird Park - Foz do Iguaçu / PR - Brazil, where the environmental education is highly valued. The institution focuses on the conservation of endangered bird species from the Atlantic Forest, and on the formation of critical thinking for its visitors. Reflections were made on the role of environmental education in these spaces and various contributions were reported for the formation of more engaged environmental educators, as well as these spaces sensitize visitors and stimulate changes in attitudes towards environmental issues.

Keywords: Environmental Education; Non-Formal Spaces; Experience.

1 Universidade Estadual de Ponta Grossa (UEPG). E-mail: kerlenalanasantos@gmail.com

2 Universidade Estadual de Ponta Grossa (UEPG). E-mail: rodrigosilva2005@yahoo.com.br. 


\section{Introdução}

As discussões acerca da problemática ambiental são bastante antigas. Platão já relatava em seus diálogos (Crítias) as consequências nefastas da ação antrópica diante da destruição ambiental (PLATÃO, 1969, p.325). No entanto, apesar disto, a preocupação mais contundente com relação à crise ambiental se dá apenas por volta do séc. XX através da publicação da obra de Rachel Carson intitulada "Primavera Silenciosa" que levou às inúmeras reuniões e manifestações internacionais que tinham por objetivo discutir os problemas ambientais e tomar medidas para amenizar os mesmos. Tais conferências contaram com a participação de inúmeros países e seus Chefes de Estado.

A conferência no ano de 1972 em Estocolmo/Suécia chamada de Conferência das Nações Unidas sobre o Homem e o Meio Ambiente, que tinha por objetivo discutir os problemas ambientais e tomar medidas para amenizar os mesmos. Contou com 113 países. Produziu a Declaração sobre Ambiente Humano, ou Declaração de Estocolmo, e estabeleceu princípios para questões ambientais internacionais, incluindo direitos humanos, gestão de recursos naturais, prevenção da poluição e relação entre ambiente e desenvolvimento, estendendo-se até a necessidade de se abolir as armas de destruição em massa.

Após a conferência de Estocolmo houve outra grande conferência, chamada de Conferência de Tbilisi, que ocorreu na cidade de Tbilisi, Geórgia URSS em 1977,

constituiu-se na primeira Conferência Intergovernamental. A declaração produzida nesta reunião contém objetivos, estratégias, características, princípios e recomendações para a Educação Ambiental que foram aperfeiçoados em publicações posteriores da UNESCO em 1985, 1986, 1988 e 1989. Nesse documento encontram-se, por exemplo, recomendações para que a Educação Ambiental aconteça tanto ao nível da educação formal quanto da informal, envolvendo pessoas de todas as idades" (MORADILLO; OKI, 2004, p.332-336).

Revista brasileira educação ambiental

Há grande necessidade de abordar educação ambiental em espaços que vão além da sala de aula, pois o nosso ambiente precisa de mudanças e transformações que resultem em algo concreto, portanto, são de extrema relevância a revisão de atitudes humanas, conscientização, sensibilização e compreensão sobre os recursos naturais e um maior comprometimento. Para que isso ocorra de forma eficiente é preciso uma colaboração de diversos setores sociais tais como: pesquisadores, comunidade acadêmica, governo, instituições de ensino, profissionais capacitados e toda a comunidade em geral. A educação, entre outros setores, pode ajudar a construir essa sociedade, no 
entanto, esta é realmente uma tarefa grande demais para ficar só no âmbito escolar. Será necessária uma cooperação entre diferentes instituições educativas a partir de uma relação de complementaridade entre os diferentes espaços educativos na sociedade (GUIMARÃES; VASCONCELLOS, 2006, p.147-162).

A educação não formal pode contribuir na formação pessoal e social do aluno, fazendo-o repensar e refletir sobre determinado assunto, pode ajudar na formação crítica e a criatividade da pessoa. A educação atual demanda novas metodologias de ensino, novos olhares e formas criativas de abordagem. A discussão de temas relacionados ao exercício da cidadania, ao debate socioambiental, aos direitos humanos, à diversidade, quando transcorrida em grupos, de forma dialógica e interativa, favorece aos participantes a busca de respostas com autonomia (SILVA; CAMPOS, 2017, p.775-793).

Com relação aos espaços de educação não formal, existem alguns aspectos que os tornam fundamentais para a promoção desta proposta educacional. Isto porque o caráter de não formalidade dessas instituições permite uma maior liberdade na seleção e organização de conteúdos e metodologias, o que amplia as possibilidades da interdisciplinaridade e contextualização (GUIMARÃES; VASCONCELLOS, 2006, p.147-162).

Portanto, o presente trabalho busca relatar a experiência da autora no Estágio de Verão no Departamento de Educação Ambiental do Parque das Aves e que foi ofertado pela primeira vez na temporada de 2018/2019. Na ocasião foram realizados estudos, intervenções com o público em geral (oficinas, conversas) e produção de material didático, todos serão mais bem descritos a seguir.

\section{Percurso metodológico}

\section{Abordagem metodológica}

Trata-se de um estudo descritivo, no formato de relato de experiência, elaborado no contexto da vivência no programa de estágio do Parque das Aves, o qual tinha por objetivo propiciar o acompanhamento da rotina do Departamento de Educação Ambiental, contribuindo para a formação acadêmica e profissional na área de educação ambiental e conservação de animais silvestres que estavam sob os cuidados humanos.

De acordo com Oliveira Lopes (2012),

um relato de experiência pertence ao domínio social, fazendo parte das experiências humanas, devendo conter tanto impressões observadas quanto conjecturadas. Este tipo de estudo é importante para a descrição de uma vivência particular que suscitou reflexões novas sobre um fenômeno específico. 


\section{Descrição do local}

O Parque das Aves está localizado na cidade de Foz do Iguaçu/PRBrasil e é uma instituição privada e foi fundada em 1994 pelo casal AnnaSophie Helene e Dennis Croukamp. Este local tem uma extensão de 16 hectares, toda a sua vegetação é nativa e mantém mais de 1.400 aves, de cerca de 150 espécies, sendo mais de $50 \%$ proveniente de apreensões. Hoje, sendo hoje a única instituição do mundo focada na conservação das aves da Mata Atlântica, auxilia no processo de preservação de espécies em ameaça de extinção, além de toda a equipe multidisciplinar deste local contribuir com diversos projetos ambientais de conservação de espécies e da Mata Atlântica.

O Parque das Aves que conta com mais de 200 funcionários tem grande atuação no campo da Educação Ambiental, desde a formação dos seus profissionais e estagiários, até a mediação e intervenção com o público. Sendo um Centro de Conservação Integrada de Espécies da Mata Atlântica, desenvolve ações de pesquisa, conservação, lazer e educação, contribuindo para a conexão de seu público visitante com a natureza. Acreditando que a educação é essencial no processo de conservação das espécies, a instituição possui o Departamento de Educação Ambiental, que tem como objetivo contribuir para a conexão do público visitante com a Mata Atlântica no sentido de permitir seu engajamento e mudanças de atitudes (Parque das Aves, 2019).

Além disso, as ações educativas que acontecem dentro do Parque contribuem com outros projetos como, por exemplo, Aves do Iguaçu, Projeto Papagaio Verdadeiro, Projeto Papagaio Chauá, Projeto Harpia, Projeto Jacutinga. Participa também do PAN - Plano de Ação Nacional para reprodução e possível reintrodução do mutum-de-Alagoas no Nordeste de onde ele é nativo e já não existe mais em vida livre.

Outros dois importantes projetos desenvolvidos no local são: (i) os "Guardiões da Mata Atlântica" o qual busca ensinar a crianças de 7 a 10 anos através de diversas atividades no Parque, além de demonstrar a importância da Mata Atlântica, bem como preservá-la; (ii), o projeto "SOS Fauna" que tem por objetivo a formação de professores na Educação Ambiental, e leva os educadores de Foz do Iguaçu para várias experiências dentro do Parque para que eles aprendam diferentes metodologias de ensino sobre a Educação Ambiental em espaços formais. Assim, tem sido desde sua criação, um espaço fundamental para o ensino de Educação Ambiental.

\section{Descrição das atividades}

O estágio foi realizado no Departamento de Educação Ambiental no período de 17/02/19 à 17/03/19, das $08 \mathrm{~h} 30 \mathrm{~min}$ às $17 \mathrm{~h} 30 \mathrm{~min}$, com duas folgas semanais, e com supervisão da coordenadora do Departamento de Educação Ambiental, Sra. Camila Martins. 


\section{Acompanhamento de programações especiais de férias para público espontâneo}

As atividades inicialmente foram relacionadas ao acompanhamento dos visitantes por meio de visitas guiadas, as quais eram realizadas pelos educadores do Departamento de Educação Ambiental local. Durante a atividade, os grupos eram guiados por uma trilha e recebiam informações sobre os animais, o ambiente, a importância da conservação da natureza e podiam tirar dúvidas.

Nesse momento, além da apresentação de todas as espécies que estavam na trilha, havia um enfoque na conservação dos mesmos, nas ameaças aos animais devido às intervenções humanas, sobre a sua importância ecológica e como nossas atitudes podem contribuir na conservação da fauna e da flora, seja com participação voluntária em projetos ou até mesmo a divulgação dessas informações para mais pessoas, para que essa corrente da Educação Ambiental se espalhe por muitos lugares.

$\mathrm{Na}$ literatura, Kisiel (2005: 936-955) comenta a importância das visitas guiadas, num estudo de referência recorrentemente citado na literatura (Tal et al., 2005, p.920-935), onde são relatadas oito motivações principais: ligação ao currículo escolar; expor os/as alunos/as a novas experiências; proporcionar uma experiência de aprendizagem; promover o interesse e a motivação dos/as alunos/as; oferecer uma mudança de rotina; promover a aprendizagem ao longo da vida; conceder uma recompensa aos/às estudantes; satisfazer as exigências das escolas. Ou seja, as visitas guiadas, sejam para qualquer público, têm o papel de ser uma atividade diferenciada, ou seja, que fuja da rotina do público e que busque um ensino com qualidade, já que sempre preferencialmente terá um profissional capacitado à frente da visita, motivando os visitantes a formarem uma consciência mais crítica sobre o assunto.

\section{Organização e participação em exposições para público espontâneo}

Outra atividade realizada durante a vivência foi a participação em uma "Oficina de Marcadores", a qual era voltada para crianças que visitavam o Parque.

Ela era realizada no meio da trilha, e as crianças que tinham interesse podiam realizar a atividade, juntamente com educadores do departamento. Particularmente, auxiliei algumas crianças na hora da confecção dos marcadores de livros, ali, havia uma interação, onde conversávamos sobre o Parque e as curiosidades que as crianças tinham sobre alguns animais. Havia crianças de diversas nacionalidades, e pude interagir com todas elas.

As oficinas possibilitam uma estimulação do saber ao criar e recriar situações, materiais, ferramentas e conhecimentos baseando-se na relação do sujeito com o objeto de estudo em questão. Esse tipo de estratégia possui um 
enorme potencial pedagógico quando usado com sabedoria, o que poderia significar uma ótima estratégia para trabalhar determinados assuntos dentro do Ensino de Ciências (SOUZA, 2016).

\section{Produção de material educativo}

Durante o estágio foi sugerida a proposta de criar um guia de espécies de um determinado viveiro dentro do Parque das Aves, sendo este material um produto do estágio. O guia deveria conter informações sobre todas as espécies desse viveiro.

Em toda a realização do projeto foram realizadas pesquisas de campo, com observações do ambiente, dos animais, e em conversas com os outros profissionais do Parque. Tudo era anotado para que servisse de base para a elaboração do guia.

Foram feitas também pesquisas bibliográficas, com informações dos animais, e do Parque, através de sites e livros. Após a obtenção de todas as informações necessárias, foi elaborado o guia, com textos simples e fáceis de entender. O guia possui informações sobre os animais (nome popular, nome científico, nome em inglês e espanhol, distribuição, hábitos, alimentação, importância ecológica e curiosidades, juntamente com uma foto do animal), e também algumas informações adicionais. Tudo isso compõe um material didático que foi feito para uso dos monitores do Parque. Depois de pronto ele foi impresso e plastificado e já colocado em uso.

Ao final do estágio, foi elaborada uma apresentação sobre o material didático produzido e sobre as experiências vividas dentro do Parque das Aves (Figura 1). Na Figura 1A é possível observar que a apresentação foi elaborada em formato Power Point e apresentada para os educadores ambientais, alguns monitores e coordenação do Departamento de Educação Ambiental do Parque, como mostra a Figura 1B. Essa apresentação foi feita no dia 14 de março de 2019, uma quinta feira, e penúltimo dia de estágio.

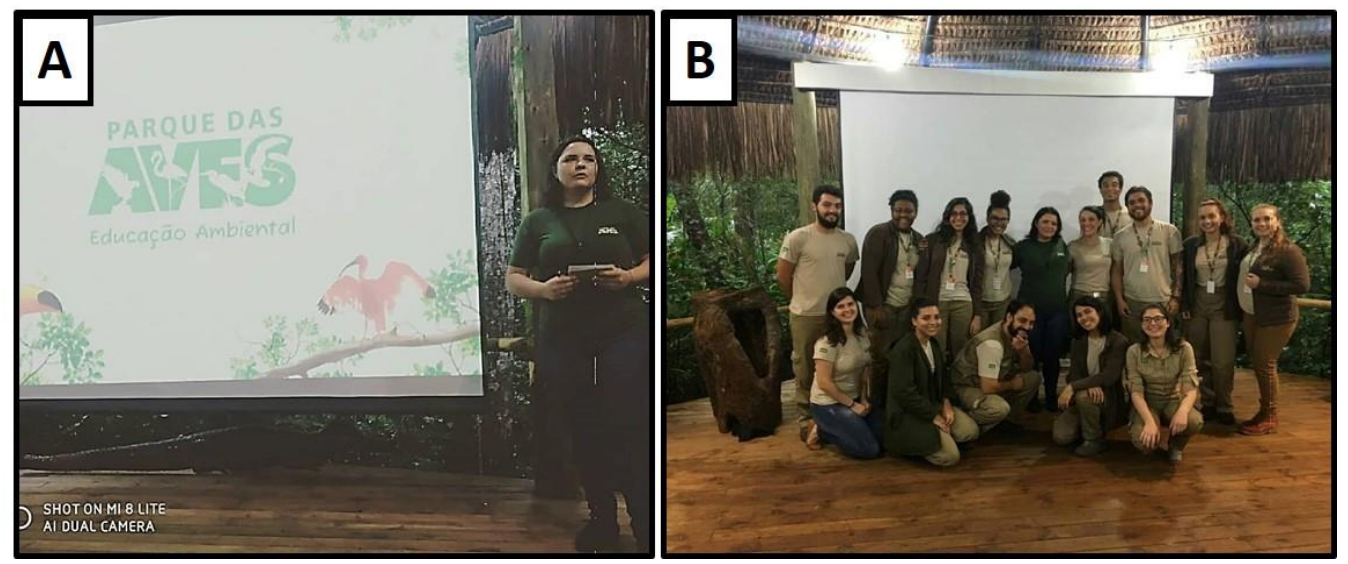

Figura 1: (A) Apresentação do material didático. (B) Parte da equipe do departamento de educação ambiental, no dia da apresentação do projeto que realizei e meu penúltimo dia de estágio. Fonte: os autores. 
Nas Figuras 2, 3 e 4 pode-se observar a estrutura do guia produzido, com: capa e estrutura interna.

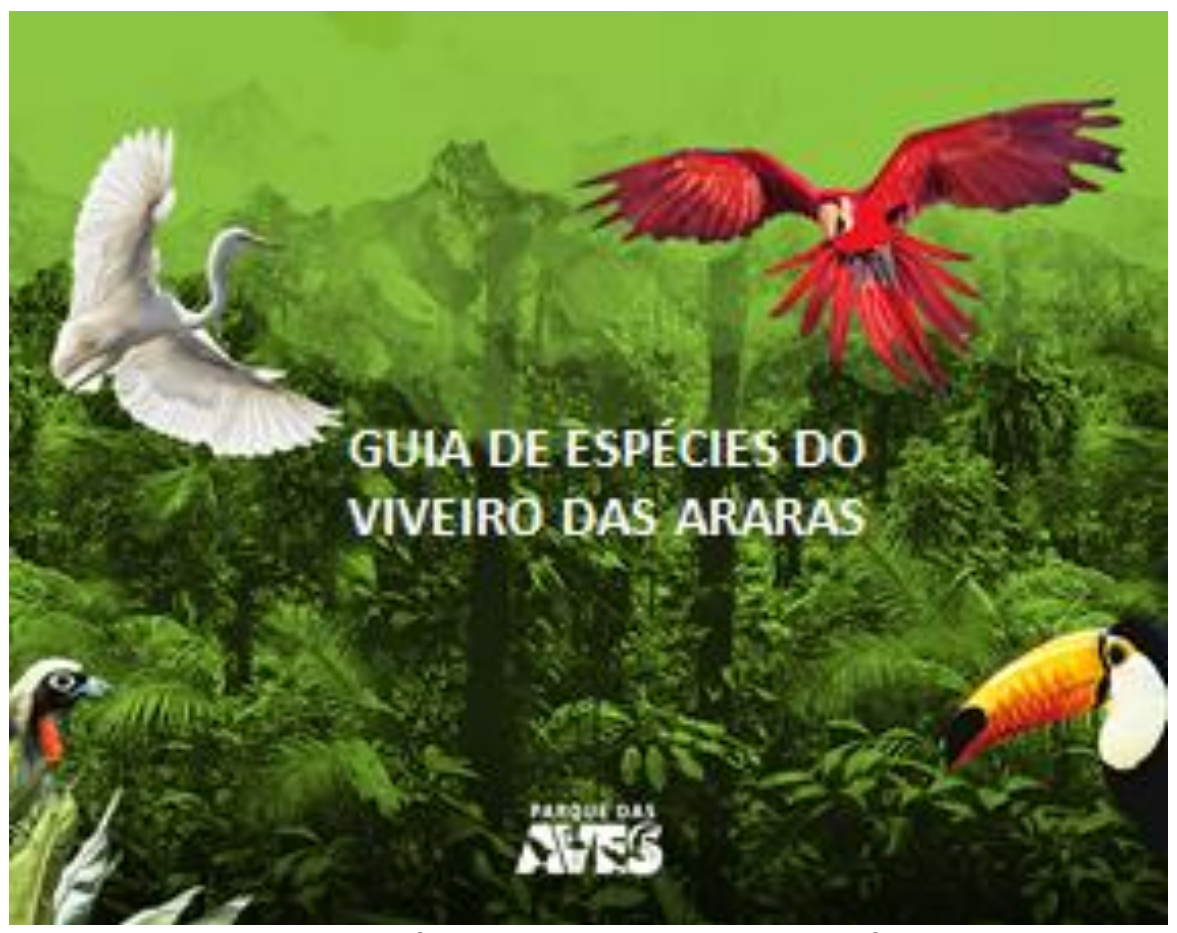

Figura 2: capa do guia de espécies produzido durante o estágio. Fonte: os autores.

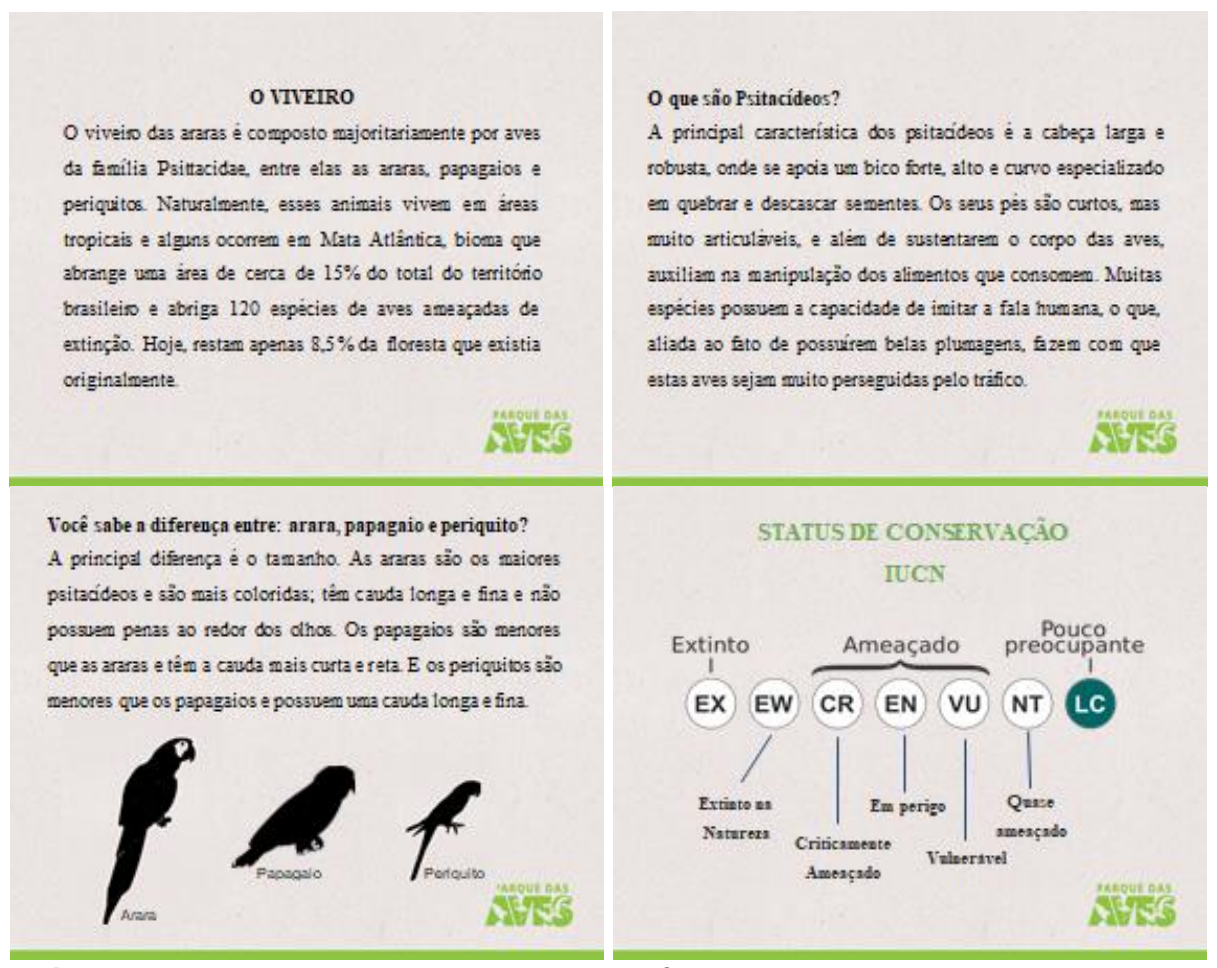

Figura 3: estrutura interna de algumas páginas do guia. Fonte: os autores.

Revbea, São Paulo, V. 16, № 2: 153-162, 2021. 


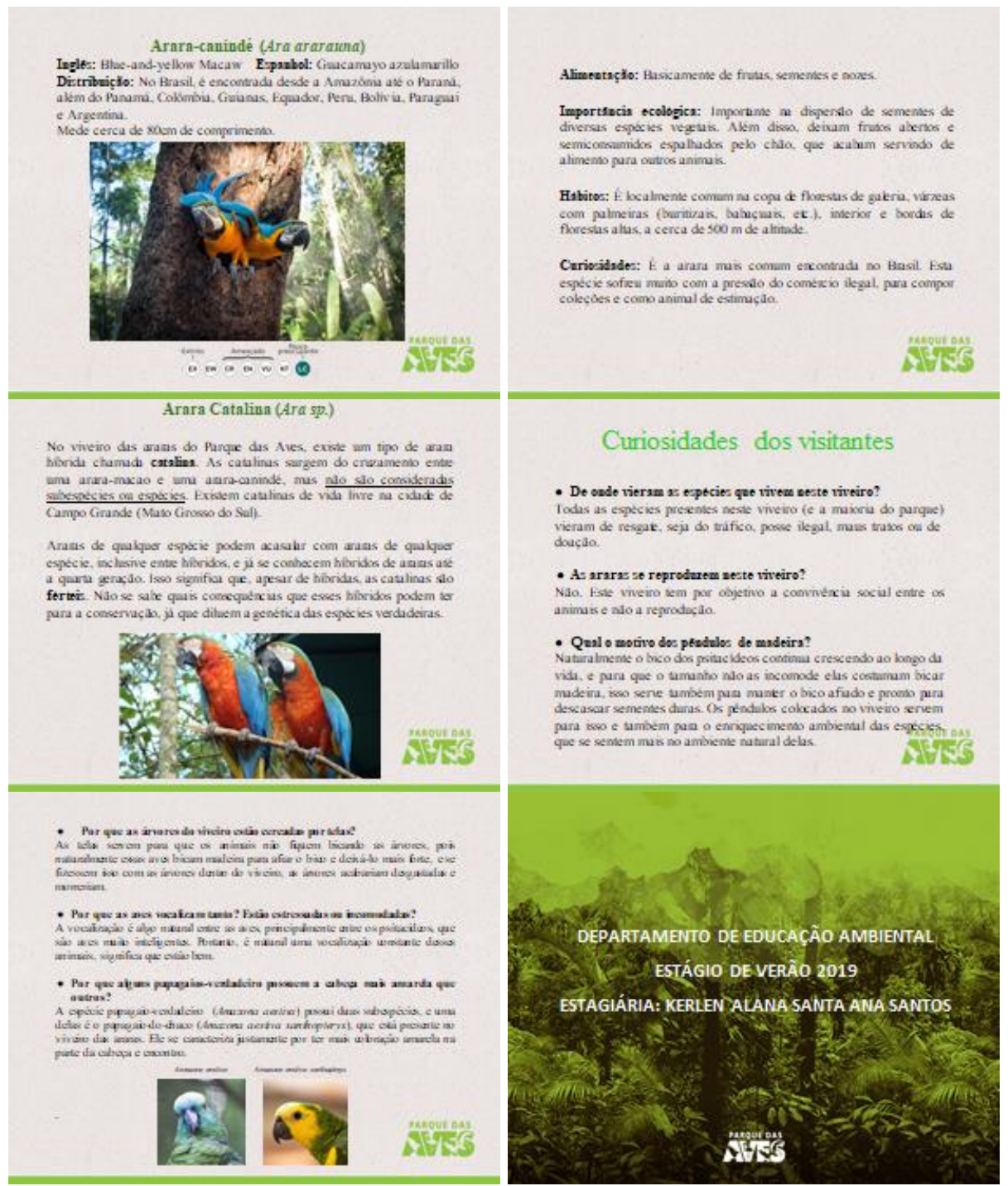

Figura 4: estrutura interna de outras páginas do guia. Fonte: os autores.

\section{Considerações finais}

O objeto de trabalho da Educação Ambiental é o ser humano, e a possibilidade de atividades diferenciadas e guiadas por profissionais capacitados nesses espaços, como o Parque das Aves, faz com que esses espaços sejam um grande potencializador para a Educação Ambiental atualmente, pois propiciam momentos e sensações aos visitantes que os leva muito além de só conhecimento, mas leva a sentirem e vivenciarem e o quão importante são as suas ações, por mais simples que sejam, desde a sua visita àquele local, mudanças no seu dia a dia, até o possível envolvimento em projetos de conservação. Nessa perspectiva é fundamental que por meio da Educação Ambiental se construa mentes comprometidas e sensibilizadas com o meio ambiente. O Parque das Aves, que foi objeto de estudo neste trabalho, 
se empenha para que os visitantes transformem atitudes e construam uma nova visão sobre a conservação da Mata Atlântica.

A partir das atividades desenvolvidas dentro do Parque se percebe o comprometimento dos colaboradores de lá, e isso é de extrema importância para que as ações tragam os resultados esperados. O papel da Educação Ambiental nos espaços de educação não formal é levar uma visão de mundo inovadora, onde as ações sejam educativas e ao mesmo tempo atrativas às pessoas.

As visitas guiadas tentam levar as pessoas a uma consciência ecológica, já as oficinas levam de uma forma lúdica curiosidades e a importância da preservação das espécies. Todas essas interações entre as pessoas, 0 ambiente social e ambiente natural é que fazem a diferença e estimulam um olhar diferenciado para as relações humanas com o meio ambiente.

Por fim, o aprendizado adquirido neste local proporcionou uma nova dinâmica que pode ser abordada nos diferentes locais e seus diferentes contextos. Além de contribuir também na minha formação, essa experiência estimulou minha busca por conhecimento na área, a minha futura formação continuada na Educação Ambiental, e principalmente a não desistir de levar às pessoas uma conscientização sobre conservação do ambiente natural, pois por mais difícil que seja muitas vezes, é possível e necessário.

\section{Referências}

CONFERÊNCIA DAS NAÇÕES UNIDAS PARA O MEIO AMBIENTE HUMANO. De Estocolmo, à Rio-92: agenda ambiental para os países e elaboração de documentos por Comissão Mundial sobre Meio Ambiente e Desenvolvimento. Em discussão, Brasília, 11 de jun. de 2012. Disponível em: $<$ http://www.senado.gov.br/noticias/Jornal/emdiscussao/rio20/ario20/conferencia-das-nacoes-unidas-para-o-meio-ambiente-humanoestocolmo-rio-92-agenda-ambiental-paises-elaboracao-documentos-comissaomundial-sobre-meio-ambiente-e-desenvolvimento.aspx>. Acesso em: 25 de mar. de 2019.

GUIMARAES, M.; VASCONCELLOS, M.M.N. Relações entre educação ambiental e educação em ciências na complementaridade dos espaços formais e não formais de educação. Educ. rev., Curitiba , n. 27, p. 147-162, June 2006.

KISIEL, J. Understanding elementary teacher motivations for science fieldtrips. Science Education, v.89, n.6, 2005, p.936-955.

MORADILLO, E.F.; OKI, M.C.M. Educação ambiental na universidade: construindo possibilidades. Quím. Nova, São Paulo, v. 27, n. 2, p. 332-336, apr. 2004.

OLIVEIRA, M.L. Sobre estudos de caso e relatos de experiências. Revista da Rede de Enfermagem do Nordeste, vol. 13, no. 4, 2012. 
PARQUE DAS AVES. Descubra um pouco mais sobre a história do Parque das Aves. 2019. Disponível em: <https://www.parquedasaves.com.br/sobre-oparque-das-aves/historia/?lang=pt>. Acesso em: 27 de jun. 2019.

PARQUE DAS AVES. Educação para conservação. 2019. Disponível em: $<$ https://www.parquedasaves.com.br/nosso-trabalho/educacao-ambiental/>.

Acesso em: 08 de set. 2019.

PARQUE DAS AVES Os números de um lugar tão impressionante não poderiam ficar atrás. 2019. Disponível em: <https://www.parquedasaves.com.br/sobre-o-parque-das-aves/numeros/>. Acesso em: 27 de jun. 2019.

PARQUE DAS AVES Trabalhe conosco. 2019. Disponível em: $<$ https://www.parquedasaves.com.br/sobre-o-parque-das-aves/trabalhe-conosco/>. Acesso em: 27 de jun. 2019.

PLATÃO. Diálogos: Sofista, Político, Filebo, Timeu, Crítias. Portugal: Publicações Europa-América, 1969.

SARAIVA, R.V. O zoológico como um espaço de ciência para a sensibilização de estudantes sobre a temática biodiversidade brasileira. 2017. $89 f$. Dissertação de mestrado - Universidade Federal de Minas Gerais, Belo Horizonte, 2017.

SILVA, M.S.; CAMPOS, C.R.P. Atividades investigativas na formação de professores de ciências: uma aula de campo na Formação Barreiras de Marataízes, ES. Ciênc. educ. (Bauru), Bauru , v. 23, n. 3, p. 775-793, jul. 2017.

SOUZA, V.A. Oficinas pedagógicas como estratégia de ensino: uma visão dos futuros professores de ciências naturais. 2016. 35f. Trabalho de conclusão de curso - Universidade de Brasília. Planaltina, 2016.

TAL, R.; BAMBERGER, Y.; MORAG; O. Guided school visits to natural history museums in Israel: Teachers' roles. Science Education, v.89, n.6, p.920-935. 